\title{
Fatores Relevantes na Contratação de Serviços em Terminais Intermodais para Granéis Agrícolas
}

\author{
Ricardo Silveira Martins ${ }^{1}$, Débora da Silva Lobo $^{2}$, \\ Alexandre Florindo Alves ${ }^{3}$ e Renato Luiz Sproesser ${ }^{4}$
}

Resumo: Este estudo procurou investigar quais são os construtos desejados pelos embarcadores nos serviços de terminais intermodais de granéis agrícolas. Esta resposta pode ajudar a compreender porque o País de dimensões continentais, que produz majoritariamente e movimenta produtos de baixo valor agregado a longas distâncias, utiliza principalmente a modalidade rodoviária. Abordando 40 embarcadores da região Sul do Brasil, utilizando a técnica multivariada de Preferência Declarada, os construtos foram ranqueados na seguinte ordem: confiabilidade, prazo, relações com cliente, custo e flexibilidade. Os resultados sinalizam que, comparativamente, construtos associados à qualidade do serviço estão recebendo valoração superior ao frete. Isto implica novas referências para o mercado de transporte, que deve indicar aumento do uso de contratos e relacionamentos de longo-prazo e redução de contratação de carreteiros.

Palavras-chaves: Intermodalidade, logística agroindustrial, nível de serviço.

\begin{abstract}
This study sought to investigate the constructs that are desired by shippers in intermodal terminal services for bulk agricultural. This response may help to understand why a continental country, which mainly produces and moves products with low added value over long distances mainly by road transport. Approaching 40 shippers in Southern Brazil, using a multivariate technique Stated Preference, the constructs were ranked in the following order: reliability, time, customer relations, cost and flexibility. The results indicate that, comparatively, constructs associated with the quality of service are obtaining higher valuation instead of freight rate. This implies new trends for the transportation market, indicating increasing use of contracts and long-term relationships and reduction of hiring carters.
\end{abstract}

Key-words: Intermodal, logistics agribusiness, service level.

Classificação JEL: R41.

1. Universidade Federal de Minas Gerais (CEPEAD/UFMG). Professor do Centro de Pós-Graduação e Pesquisa. E-mail: martins@cepead.face.ufmg.br

2. Universidade Estadual do Oeste do Paraná. Professora do Programa de Pós-Graduação em Desenvolvimento Regional e Agronegócios. E-mail: dslobo@uol.com.br

3. Universidade Estadual de Maringá. Professor do Programa de Pós-Graduação em Ciências Econômicas. E-mail: afalves@uem.br

4. Universidade Federal de Mato Grosso do Sul. Professor do Departamento de Economia e Administração e do Programa de Pós-graduação em Administração. E-mail: drls@nin.ufms.br 


\section{Introdução}

O agronegócio brasileiro apresenta, há tempos, números de extrema relevância relativos tanto ao crescimento quanto à participação nos mercados mundiais. A produção nacional de grãos já está próxima de 200 milhões de toneladas e o País lidera a produção e exportação mundial de café, açúcar, etanol e suco de laranja (MAPA, 2011).

Porém, o esforço de pesquisa de novas variedades de plantas, defensivos agrícolas, maquinários, manejo e a eficiência dos produtores não têm respaldo na infraestrutura disponível. Desta forma, muitas vezes as vantagens comparativas são fortemente corroídas ou mesmo perdidas por ineficiências provocadas por carências da infraestrutura, marcadamente, pela insuficiência das malhas ferroviária e hidroviária, pela baixa qualidade do sistema rodoviário e pelo atraso tecnológico e rigidez do sistema portuário.

Isto porque a produção agroindustrial tem crescido em direção ao interior do País, distanciando-se dos portos, que são os pontos de acesso aos mercados externos. Os agronegócios brasileiros têm expandido sua ocupação para as regiões Norte e Centro-Oeste e enormes áreas do Nordeste. Também estão mais distantes as fontes e os fornecedores de alguns insumos e implementos utilizados na produção, os quais demandam maior quantidade de serviços de transporte.
Este processo provoca um crescimento da demanda por transportes e logística, como um todo. Em algumas situações, o problema de logística pode ser identificado na insuficiência de estruturas de armazenamento nas regiões produtoras e nos portos, causando forte sazonalidade nos fretes e filas de veículos para carregar e descarregar. Em outros, o problema é mais diretamente relacionado ao elevado frete pago entre a origem e o porto em relação aos preços recebidos pelos produtores.

No que diz respeito ao âmbito dos sistemas de transporte e da logística, esta problemática pode ser identificada na extremada concentração da movimentação de mercadorias por rodovias, muitas vezes pela simples indisponibilidade de outras modalidades. Isso contraria a lógica econômica que recomendaria que os grandes volumes de cargas para percorrerem longas distâncias, com bens de baixos quocientes valor/frete, deveriam ter como mais adequados arranjos logísticos que contemplassem, ao menos parcialmente no percurso, as modalidades hidro e ferroviária (MARTINS e CYPRIANO, 2004).

Neste aspecto, a operação dos terminais intermodais tem papel peculiar. O terminal representa um elo potencialmente facilitador no uso de modalidades mais apropriadas para a movimentação de grandes quantidades a longas distâncias, mas que não têm a seu favor o atributo "capila- 
ridade", ou seja, não chegam necessariamente próximas dos pontos onde ocorre a produção. Podem posicionar-se estrategicamente em pontos intermediários para captar a produção pulverizada, reunir grandes volumes e expedi-los para os portos de destino.

Se operado de forma eficiente e a baixos custos, o terminal intermodal pode agir como um elemento catalisador, proporcionando operações de menor custo ao dar a oportunidade de acesso a uma modalidade de maior capacidade de carga. Porém, se sua operação não estiver de acordo com expectativas e necessidades da demanda, por questão de custos ou de confiabilidade, por exemplo, os embarcadores poderão ser indiferentes à oferta, preferindo a operação de modalidades eventualmente mais caras, mas confiáveis.

Esta é então a pergunta que a pesquisa objetiva responder: quais são os construtos desejados pelos embarcadores nos serviços de terminais intermodais de granéis agrícolas?

$\mathrm{Na}$ abordagem tradicional, a gestão do transporte é discutida mais como um processo (NG, FERRIN e PEARSON, 1997; NEUSCHEL e RUSSELL, 1998) e seu fluxo é medido em sua performance operacional e custos (MEIXELL e NORBIS, 2008; MASON et al., 2003; MCCANN, 2001). Neste artigo, o transporte é analisado enquanto gestão de serviços, procurando entender como os embarcadores formam suas expectativas quanto aos serviços.

O tema abordado tem impactos significativos no cotidiano das organizações. A gestão do transporte implica a tomada de decisões sobre como movimentar materiais e produtos acabados entre diferentes pontos de uma determinada rede de negócios. Como componente da logística, as expectativas quanto ao desempenho do serviço de transportes se tornaram mais complexas. A busca da eficiência dos processos logísticos fez com que outros atributos do serviço fossem incorporados ao bojo da tomada de decisão acerca dos transportes, como o cumprimento dos prazos, a transparência de custos e o desenvolvimento de serviços apropriados e integrados com fornecedores e clientes.
Desta forma, tendo como pano de fundo o impacto dos serviços de transportes no nível competitivo dos negócios, este estudo buscou analisar os fatores relevantes na tomada de decisão pela contratação dos serviços de transporte.

A elucidação destas questões apresenta relevância social, gerencial e acadêmica. Em termos sociais, a resposta à questão da pesquisa interessa pelo conhecimento da realidade de um país de dimensões continentais que não tem práticas de intermodalidade e que movimenta suas cargas majoritariamente por rodovias, sendo que, em tese, boa parte destas cargas poderia estar embarcada em outra(s) modalidade(s). Isso onera o sistema rodoviário e a logística de outros setores de atividade econômica, na forma, principalmente, de aumento de nível de estoques. Em termos gerenciais, o estudo utiliza uma técnica rigorosa, mas que apresenta resultados relativamente rápidos para as organizações alinharem-se nos relacionamentos com clientes e fornecedores e responderem de forma mais adequada a expectativas e necessidades, permitindo aprimoramentos futuros nos processos de gestão, aplicando ao caso dos terminais intermodais. No âmbito acadêmico, o estudo contempla técnica de análise multivariada aplicada para a compreensão de comportamento de agentes do agronegócio brasileiro, área em que a pesquisa vale-se muitas vezes de técnicas determinísticas e de modelagem, sem a adequada refinada atenção às expectativas diferenciadas de grupos de embarcadores e suas prioridades em termos de formação do pacote de serviços desejado.

O presente estudo está estruturado de forma que, além dessa introdução, é apresentado, na segunda seção, o referencial teórico tratando da logística como estratégia de negócios, seguido da natureza da pesquisa e os procedimentos metodológicos adotados para alcançar os objetivos propostos, com detalhamento nas estratégias e ações utilizadas na pesquisa na aplicação da técnica de Preferência Declarada. Em seguida, são apresentados e discutidos os resultados alcançados com a pesquisa, detalhando as características dos terminais intermodais da região estudada, os 
resultados referentes aos construtos, bem como a discussão destes resultados. Por fim, são elaboradas as conclusões do trabalho.

\section{Logística como instrumento na estratégia competitiva de negócios}

De acordo com o Council of Supply Chain Management Professionals - CSCMP (2009), o termo logística é definido como "o processo de planejamento, implantação e controle do fluxo eficiente e eficaz de mercadorias, serviços e das informações relacionadas, desde o ponto de origem até o ponto de consumo, procurando sempre atender as necessidades dos clientes."

Essa é uma definição bem recente para uma das atividades mais antigas da humanidade. Como os recursos destinados ao consumo humano geralmente estavam em lugares distantes das populações, o homem sempre se ocupou de transportar e estocá-los. Mesmo com os avanços tecnológicos em conservação e transporte, a racionalização logística não perdeu sua importância dentro dos estudos e preocupações humanas, ela sempre foi alvo de estudos das organizações militares, distribuidores de alimentos e produtos industrializados.

A logística brasileira, tradicionalmente vista apenas como entrada, saída e armazenagen, passou a incorporar os processos e suas atividades das formas de movimentos de produtos, informações, pessoas etc. Toda a gestão de fluxos entre funções de negócios foi incorporada pela logística (DORNIER et al., 2000).

A área empresarial foi beneficiada pelo desenvolvimento da logística enquanto estratégia do meio militar, muito embora já em 1901, John F. Crowell ${ }^{5}$ tivesse manifestado suas preocupações com elementos da logística, abordando os custos e os fatores que afetam a distribuição de produtos agrícolas. No conceito militar, logística engloba uma compreensão do planejamento e implementação de estratégias para vencer o ini-

5. Report of the Industrial Commission on the Distribution of Farm Products, vol. 6 (WASHINGTON, D. C.: GOVERNMENT PRINTING OFFICE). migo, inovando em formas de dispor os exércitos e seus suprimentos, conjugada com operações de suporte de provisão aos exércitos de armamentos, de munições, de materiais, de pessoal, de alimentos e com avanço das instalações.

A logística aplicada ao universo empresarial consiste em idealizar e implementar formas de colocar os produtos e serviços disponíveis nos mercados, na forma, nas quantidades e nos momentos que estes manifestam desejos de consumi-los, de uma forma melhor (custos e/ou nível de serviços) do que fazem os concorrentes.

A logística vista como um conjunto de atividades elementares criadoras de valor intra e inter empresas atua como fator-chave de sucesso no desempenho superior de sistemas produtivos. Tradicionalmente, tais atividades são identificadas como estoque, transporte, instalações e informação. Estas atividades contribuem, sobremaneira, à melhoria das operações (CHOPRA e MEINDL, 2003) e para a competitividade dos negócios.

Para os embarcadores, os serviços de transportes são, em geral, o pilar do composto da distribuição, pois impactam diretamente a satisfação do cliente. Numa situação de determinada organização de produtos competitivos, a logística (entrega) pode impactar negativamente a avaliação global (produtos e serviços agregados) feita pelo cliente, por exemplo, podendo implicar perda de fidelidade ou não repetição da compra, conforme o desempenho das entregas em custo, nível de avarias, prazos e consistência geral dos serviços (BALLOU, 2006).

Segundo Wanke e Zinn (2004), a criação do valor, ou seja, a criação de um produto ou serviço ou de suas características que tornam desejável o consumo pode acontecer em alguns momentos. Cabe à logística entregar o valor a quem tem interesse na posse do produto. Para isso, devem-se agregar os valores de lugar e tempo. $\mathrm{O}$ valor de lugar implica disponibilizar o produto no local mais apropriado para realizar o desejo de posse, seja este uma loja de varejo ou atacadista ou ainda a casa ou instalações do cliente. O valor de tempo implica que o ato de transferência de propriedade deve ser realizado no momento desejado. 
No caso do formato do agronegócio tratado neste artigo, granéis agrícolas, o valor é principalmente criado pelo transporte, dentre as atividades-chave da logística destacadas anteriormente. Bowersox, Closs e Cooper (2002) sugerem que a gestão dos transportes deva ser executada pela avaliação dos serviços de transporte baseados em parâmetros que permitam demonstrar o desempenho, por exemplo, em:

- Velocidade: tempo gasto em trânsito

- Disponibilidade: capacidade de atender a qualquer origem e destino

- Confiabilidade: potencial de variação no tempo total de prestação do serviço

- Capacidade: condição de manipular qualquer carga e em qualquer quantidade

- Frequência: capacidade de atender a qualquer momento

A eficiência de escoamento dessa produção a um baixo custo torna-se estratégica para as organizações e um grande desafio para a logística (CAIXETA-FILHO e GAMEIRO, 2001). Um sistema de transporte eficaz irá refletir escolhas dentre as modalidades, sendo que cada uma delas tem características que podem e devem ser exploradas na elaboração de estratégias de transporte. As modalidades de transporte clássicas e respectivas características, de acordo com Demaria (2004), são:
- Aquaviário: alta capacidade a custos baixos e baixa agilidade e flexibilidade;

- Rodoviário: agilidade e flexibilidade, mas os custos variáveis são elevados;

- Ferroviário: capacidade média, agilidade média, baixa flexibilidade e custo médio.

- Aéreo: rapidez, baixa capacidade de carga, custos elevados e alta flexibilidade.

- Dutoviário: baixa flexibilidade, baixa agilidade e baixos custos.

Porém, muitas vezes, restrições de dotações naturais ou de escala fazem com que os sistemas de transporte se estruturem em hubs. Desta forma, uma estrutura de embarque no sistema ferroviário é implantada em determinado ponto estratégico, por exemplo, abrangendo um raio de $500 \mathrm{~km}$ de captação de cargas para consolidação para a operação ferroviária. É o que se chama de Intermodalidade. Então, intermodalidade implica o uso de mais de uma modalidade de transporte de uma mercadoria entre a origem e o destino.

Como no caso acima, o modal rodoviário serve como principal integrador entre modalidades porque tem grande capilaridade. No entanto, a transferência de cargas entre modalidades demanda uma estrutura física que dê suporte para que a operação de transferência possa ocorrer rapidamente, com um baixo custo, sem perdas e avarias das cargas (Figura 1).

Figura 1. Representação simplificada de um terminal de transbordo em operação

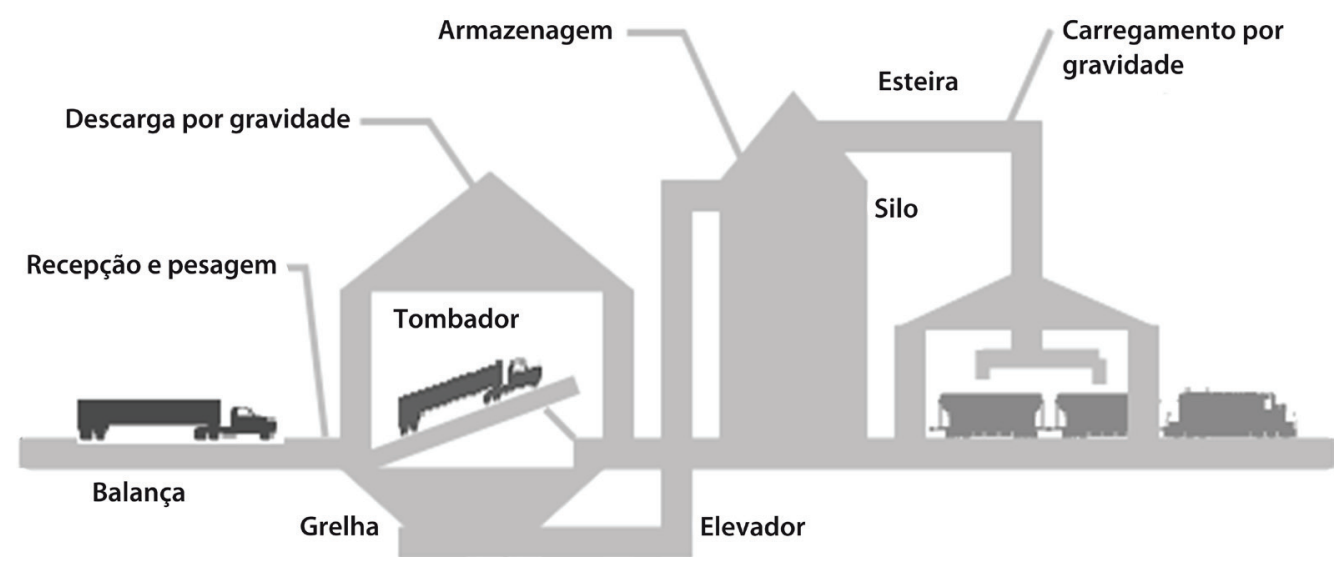

Fonte: Calabrezi (2005). 
Caixeta-Filho (2006) aponta que, na movimentação de grãos no Brasil, há o predomínio do transporte rodoviário de autônomos e ocorre, geralmente, a granel. Muitas vezes, esses transportadores são ligados a empresas de transporte rodoviário. Os veículos utilizados são, principalmente, carretas e bi-trens com capacidade de 27 e 40 toneladas, respectivamente.

\section{Definições metodológicas}

Este estudo é uma pesquisa empírica, de caráter exploratório, que procurou caracterizar as necessidades e expectativas dos embarcadores quanto aos serviços prestados pelos terminais intermodais para operações de granéis agrícolas. Essa pesquisa foi conduzida segundo critérios propostos por Collis e Hussey (2009): quanto aos seus objetivos, constitui um estudo exploratório; quanto ao processo, este estudo é quantitativo e, quanto à lógica, se classifica como pesquisa indutiva. $\mathrm{O}$ tipo de metodologia de procedimento é o survey, com amostragem não probabilística por acessibilidade.

Malhotra (2001) destaca que a pesquisa exploratória é adequada em áreas de poucos conhecimentos acumulados, quando a compreensão dos fenômenos ainda não é suficiente ou até mesmo inexistente. Nesses casos, o caráter empírico da pesquisa apoia-se em levantamento de dados em campo e pela utilização de fontes de pesquisa complementares.

Quanto à lógica, utiliza a indução, que é a forma de abordagem do tema, em seu raciocínio e/ou argumentação, tendo como objetivo não só a produção de pensamentos, mas de orientar a reflexão (CERVO, BERVIAN e SILVA, 2007). Ainda, de acordo com esses autores, o método indutivo busca generalizar resultados específicos de um ou certo número de casos para todas as ocorrências similares presentes ou futuras.

\subsection{Amostra}

O processo de amostragem é do tipo não probabilístico, por acessibilidade e tipicidade. A opção por essa forma de amostragem dá-se pela dificuldade de acesso às empresas. Collis e Hussey (2009) confirmam que algumas vezes é difícil obter uma amostra, particularmente quando se tratam de questões sensíveis ou que podem ser sigilosas. Nessa situação, a amostragem envolveu a seleção das unidades que aceitaram fazer parte do estudo e forneceram as informações necessárias à pesquisa (HAIR et al., 2005).

A amostragem envolveu 40 entrevistas realizadas com clientes de terminais intermodais distribuídos pelos estados do Paraná, Santa Catarina e Rio Grande do Sul. A unidade de análise de pesquisa refere-se às empresas embarcadoras usuárias ou potenciais usuárias de terminais intermodais de granéis agrícolas. As unidades de observação foram os gerentes envolvidos no processo de gestão operacional das unidades. Segundo estimativas do IBGE (2011), a região Sul lidera a produção nacional de grãos, tendo o Paraná 20,2\% de participação na produção total brasileira, o Rio Grande do Sul, 17,3\% e Santa Catarina, $4,1 \%$.

\subsection{Estratégias de pesquisa, coleta de dados e natureza das informações}

A coleta de dados ocorreu por meio de aplicação de cartões de Preferência Declarada. A estratégia de pesquisa adotada foi a visita in loco. $\mathrm{O}$ objetivo da entrevista é a obtenção de informações de um determinado assunto, sendo utilizada para realizar diagnósticos e coletar dados (MARCONI e LAKATOS, 2008). Ainda de acordo com as autoras, uma entrevista com um roteiro estruturado permite a comparação das respostas de diferentes indivíduos. Este tipo de entrevista também é conhecido como Survey.

Cervo, Bervian e da Silva (2007) comentam que esta técnica é utilizada para obter informações que não podem ser encontradas em registros ou fontes documentais, mas que podem ser fornecidas por alguém. Esses dados, segundo os autores, são utilizados como estudo de fatos, opiniões e casos.

As entrevistas abordaram questões que tratavam dos construtos e atributos do transporte. 
O ranqueamento das preferências dos embarcadores foi conhecido por meio do levantamento pela Técnica de Preferência Declarada, à qual se dedica mais atenção na próxima seção.

\subsection{Técnica de preferência declarada}

O tratamento estatístico para conhecimento das preferências dos embarcadores pode ser feito por meio de técnicas estatísticas multivariadas. Dentre elas, Análise Conjunta, de Preferência Revelada e de Preferência Declarada, esta última foi selecionada pela adequação aos propósitos do estudo. Para o desenvolvimento deste trabalho, esta técnica apresenta-se mais adequada que as demais. Isto porque lida essencialmente com situações hipotéticas ou situações nas quais as preferências ou escolhas não podem ser diretamente observadas. Segundo Almeida e Gonçalves (2001), este conjunto de opções pode ser hipotético, mas deve ser viável se efetivada, permitindo aos entrevistados imaginá-las com facilidade.

Análises de mercado que têm suporte na Preferência Declarada apoiam-se em alguns conceitos de comportamento humano na explicação das preferências manifestadas pelos agentes, tanto pessoas quanto organizações, quando esses tentam maximizar sua satisfação. Para Byrns (1996), este comportamento também é vital para tomar decisões de negócios, na tentativa de maximizar a utilização dos recursos empregados no sistema organizacional.

Segundo Ortúzar (1998), a Preferência Declarada consiste num conjunto de metodologias que se baseiam no juízo declarado por indivíduos acerca de situações hipotéticas que lhe são apresentadas. A Preferência Declarada utiliza técnicas de planejamento de experimentos para elaborar alternativas hipotéticas a serem apresentadas aos respondentes. Permite, então, analisando situações não necessariamente existentes, identificar as características relevantes para os usuários no serviço estudado.

A técnica de Preferência Declarada foi aplicada originalmente em problemas das ciências administrativas na década de 1970, na área de marketing. Segundo Louviere et al. (2000), a técnica de Preferência Declarada está sendo largamente utilizada, tanto no setor industrial quanto no comercial, e é geralmente aplicada para:

a) testar a aceitação de novos produtos ou serviços ou realizar modificações nos atuais;

b) desagregar dados de mercado obtidos via Preferência Revelada;

c) avaliar fatores subjetivos influentes na tomada de decisão.

Por meio da técnica de Preferência Declarada, é possível identificar a importância relativa de cada atributo. Como insumo estratégico, o uso destas informações possibilita posterior configuração do serviço mais próxima dos anseios dos agentes. Desta forma, alguns estudos em logística utilizaram a Preferência Declarada para conhecer a valoração de atributos relativos à qualidade dos serviços de transporte (MARTINS e LOBO, 2011; SCHMIT e LOBO, 2009; DALMAS, LOBO e ROCHA Jr., 2009; MARTINS, ARAÚJO e LOBO, 2005; MARTINS, LOBO e PEREIRA, 2005) enquanto Lobo e Conte (2012) identificam a estratégia da logística de suprimento de milho para as fábricas de ração do oeste paranaense.

\subsubsection{Levantamento das preferências dos embarcadores}

Segundo Lobo (2003), a pesquisa consiste em três passos básicos: elaboração, execução e análise. Na etapa de elaboração devem ser definidos os construtos que serão estudados e analisados no experimento, bem como quantos níveis cada um deles terá, o que determinará a complexidade do experimento. Também é necessário determinar a forma de entrevista e de análise dos dados.

\subsubsection{Entrevistas}

Na etapa de execução, o entrevistado deve ser bem esclarecido sobre o procedimento que executará com o conjunto de cartões que lhe é apresentado. Ainda segundo Lobo (2003), há três medidas de escolha para se obter a informação 
da preferência do entrevistado: choice, em que o entrevistado escolhe a melhor alternativa; rating, em que o entrevistado atribui notas às alternativas, e ranking, em que o entrevistado ordena as alternativas segundo suas preferências.

Nesse trabalho, optou-se pela forma ranking. Segundo relatos de Camargo (2000), o ordenamento é a metodologia menos cansativa para os entrevistados nas condições apresentadas. Nesse método, os blocos de cartões são apresentados separadamente e de forma aleatória e o entrevistado os ordena a partir da alternativa que lhe desperte maior utilidade.

Quanto às entrevistas, recomenda-se que devam ser realizadas através de aplicação in loco com o entrevistado em virtude de serem relativamente demoradas, mas também é possível considerar formas mistas em que o material é enviado pelo correio, com a entrevista sendo conduzida por telefone pelo entrevistador (LOUVIERE et al., 2000) ou por meio da internet.

No caso da presente pesquisa, a abordagem ocorreu pessoalmente in loco. A estratégia de pesquisa adotada foi a realização de entrevistas in loco. Segundo Craighead e Meredith (2008), estudos que usam as percepções que as pessoas têm sobre a realidade têm aumentado a participação relativa no conjunto da pesquisa em gestão de operações, num movimento de direcionamento dos pesquisadores que "saem dos seus gabinetes" em direção a uma observação mais direta do fenômeno a ser estudado, de forma que os achados terão maior relevância para os gestores e para a elucidação do problema tratado.

Para a elaboração do instrumento de pesquisa, foram buscadas orientações teóricas em torno das dimensões relevantes à avaliação do transporte em Novaes (2007), Schluter e Sena (1999) e Valente, Passaglia e Novaes (2008). Além de revisão teórica, o instrumento de pesquisa também utilizou a experiência de estudos anteriores que tiveram propósitos semelhantes, tais como ANTT (2005) e BIRD/ANTT (2006).

Os construtos e respectivos níveis são apresentados no Quadro 1.

\subsubsection{Análise dos dados}

Para analisar os dados advindos da técnica de Preferência Declarada, foi utilizado o Modelo Logit Multinomial. Admitindo-se que o termo aleatório da função utilidade (1) seja regido por

Quadro 1. Os construtos selecionados e respectivos níveis e códigos numéricos

\begin{tabular}{|c|c|c|}
\hline Construtos & Níveis & $\begin{array}{l}\text { Código } \\
\text { Numérico }\end{array}$ \\
\hline \multirow[t]{2}{*}{ Prazo } & Curto: entregas feitas rapidamente & 1 \\
\hline & $\begin{array}{l}\text { Longo: entregas feitas num prazo duas vezes mais lento que o serviço oferecido por um } \\
\text { transportador ou carreteiro }\end{array}$ & 0 \\
\hline \multirow[t]{2}{*}{ Relação com o cliente } & $\begin{array}{l}\text { Informações acessíveis: o operador oferece facilidades de comunicação e contato para ne- } \\
\text { gociação e a empresa (embarcador) tem informações sobre o status da carga em trânsito }\end{array}$ & 1 \\
\hline & $\begin{array}{l}\text { Informações dificultadas: o operador não oferece facilidades de comunicação e contato } \\
\text { para negociação e a empresa (embarcador) não tem informações sobre o status da carga em } \\
\text { trânsito no momento em que precisa }\end{array}$ & 0 \\
\hline \multirow[t]{2}{*}{ Custo } & $\begin{array}{l}\text { Satisfatório: razoavelmente inferior (mínimo } 20 \% \text { inferior) ao serviço oferecido por um } \\
\text { transportador ou carreteiro }\end{array}$ & 1 \\
\hline & $\begin{array}{l}\text { Insatisfatório: igual ou muito próximo (mínimo 10\% superior) de um serviço oferecido por } \\
\text { um transportador ou carreteiro }\end{array}$ & 0 \\
\hline \multirow[t]{2}{*}{ Confiabilidade } & $\begin{array}{l}\text { Alta: o serviço é confiável, deixando o embarcador sem preocupação quanto à pontualida- } \\
\text { de e integridade da carga }\end{array}$ & 1 \\
\hline & $\begin{array}{l}\text { Baixa: o serviço não é confiável, deixando o embarcador preocupado quanto à pontualida- } \\
\text { de e integridade da carga }\end{array}$ & 0 \\
\hline \multirow[t]{2}{*}{ Flexibilidade } & $\begin{array}{l}\text { Serviço capilar: atende a múltiplos pontos, chegando a diversos pontos de destino (clientes } \\
\text { e portos) }\end{array}$ & 1 \\
\hline & Serviço rígido: poucas rotas, poucos pontos de destino seriam atendidos pelo serviço & 0 \\
\hline
\end{tabular}

Fonte: Elaborada pelos autores. 
uma distribuição tipo Gumbel, tem-se o modelo Logit Multinomial (BEN-AKIVA e LERMAN, 1985) que pode ser escrito como:

$$
P_{n}(i)=\frac{e^{\beta_{k} X_{i n k}}}{\sum_{j \in C} e^{\beta_{k} X_{j n k}}}
$$

em que $\mathrm{P}_{\mathrm{n}}(\mathrm{i})$ é a probabilidade de a alternativa $i$ ser escolhida pelo indivíduo $n$ dentro de um conjunto de possibilidades $C$.

Foram usados recursos estatísticos para a análise das respostas pelo algoritmo desenvolvido por Souza (1999).

\section{Resultados: análise e discussão}

\subsection{Características da logística no corredor de transporte Sul}

Os corredores de transporte correspondem a segmentos dos sistemas de transporte, ligando diferentes áreas e localidades, onde exista demanda por transporte para viabilizar o fluxo de mercadorias. Em torno e ao longo dos corredores, formam-se estruturas complexas, tais como mercado de trabalho e capital, infraestrutura comercial e logística, compreendendo condições de armazenamento e distribuição, sistemas de fiscali- zação, sistemas de integração tecnológica, espaços de produção de tecnologia, sistemas de transporte complementares e, por fim, condições de acessibilidade dos mercados locais, regionais, nacionais e externos (MARTINS e LEMOS, 2006).

Em termos de infraestrutura de transporte, o corredor Sul estrutura-se com base nas modalidades rodoviária, hidroviária e ferroviária (Figura 2), tendo como pontos de destino principalmente os portos de Paranaguá (PR), São Francisco do Sul (SC) e Rio Grande (RS). Ademais, pela importância destes portos no escoamento da produção nacional, parte significativa da produção de Mato Grosso e Mato Grosso do Sul também são movimentadas pelo corredor, implicando uso potencial de terminais intermodais.

$\mathrm{Na}$ região Sul, a ferrovia América Latina Logística (ALL) configura uma das principais rotas praticadas no escoamento da safra de soja aos portos de Paranaguá (PR), São Francisco do Sul (SC) e Rio Grande (RS). O subsistema rodoviário assenta-se principalmente sobre as BRs $376 \mathrm{e}$ 277, no Paraná, que conectam os centros de produção aos de consumo e ao porto de Paranaguá. No Rio Grande do Sul, o transporte rodoviário realiza-se pelas BRs 386 e 153, que conduzem ao porto de Rio Grande. O estado também tem a hidrovia Jacuí-Lagoa dos Patos, que faz a liga-

Figura 2. Sistemas de transporte e terminais intermodais do corredor Sul

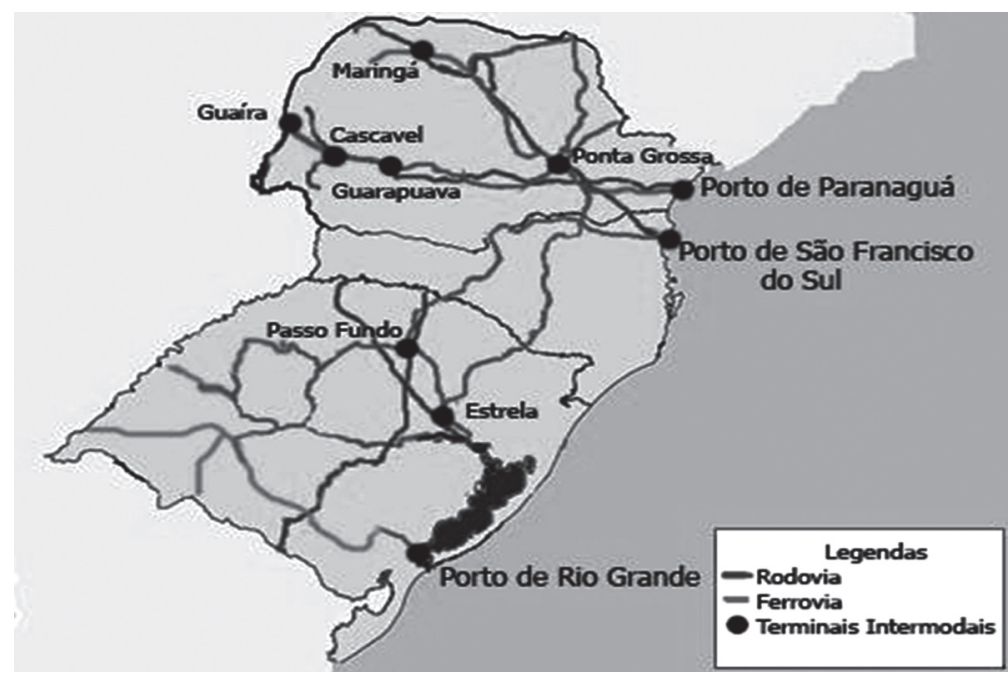

Fonte: Elaborado pelos autores com base em dados de Ojima (2004) e ALL (2012). 
Tabela 1. Terminais intermodais na região Sul do Brasil

\begin{tabular}{cc}
\hline Identificação & Localização \\
\hline A & Cascavel/PR \\
B & Guaíra/PR \\
C & Guarapuava/PR \\
D & Maringá/PR \\
E & Maringá/PR \\
F & Maringá/PR \\
G & Paranaguá/PR \\
H & Paranaguá/PR \\
I & Ponta Grossa/PR \\
J & São Francisco do Sul/SC \\
K & Estrela/RS \\
L & Passo Fundo/RS \\
M & Rio Grande/RS \\
\hline
\end{tabular}

Fonte: Dados da pesquisa.

Tabela 2. Serviç̧os prestados pelos terminais na região Sul

\begin{tabular}{llllllllllllll}
\hline \multicolumn{1}{c}{ Serviço } & A & B & C & D & E & F & G & H & I & J & K & L & M \\
\hline Pré-limpeza & & & $*$ & $*$ & & & & & $*$ & & $*$ & $*$ & $*$ \\
Limpeza & $*$ & & $*$ & & $*$ & & & & $*$ & & $*$ & $*$ & $*$ \\
Secagem & & & $*$ & & $*$ & & & & $*$ & & $*$ & $*$ & $*$ \\
Expurgo & & & $*$ & & & $*$ & & & $*$ & & $*$ & $*$ & \\
Blend & & & $*$ & & & $*$ & & & & & & $*$ & \\
Segregação & $*$ & & $*$ & $*$ & & $*$ & & & $*$ & & & $*$ & \\
Armazenagem & & $*$ & $*$ & $*$ & $*$ & $*$ & $*$ & $*$ & $*$ & $*$ & $*$ & $*$ & $*$ \\
\hline
\end{tabular}

Fonte: Dados da pesquisa.

ção dos locais que concentram a produção ao Terminal Hidroviário de porto Estrela ao porto de Rio Grande pela Lagoa dos Patos, seguindo, depois, para o porto marítimo de Rio Grande.

A região apresenta diversos terminais intermodais, parte dos quais é listada na Tabela 1.

Santos (2012), ao caracterizar os terminais intermodais da cadeia logística nacional, afirma que, para cada conexão intermodal, há uma determinada configuração de terminal. Seguindo a classificação do autor, foram encontrados três tipos distintos de terminais no corredor Sul, sendo eles:

- Terminal ferro-rodoviário: terminal G;

- Terminal rodo-ferroviário: terminais $\mathrm{A}, \mathrm{B}$, C, D, E, F, I e L;

- Terminal rodo-ferro-hidroviário: terminais $\mathrm{H}, \mathrm{J}, \mathrm{K}$ e M.

Para que o grão esteja em conformidade com os padrões mínimos exigidos para comerciali- zação, alguns serviços pós-colheita (Tabela 2) devem ser realizados. Desta forma, alguns terminais, além do transbordo (serviço oferecido por todos os terminais), oferecem outros serviços que complementam o processamento e o escoamento dos grãos. Os serviços mais comuns ofertados pelos terminais são: pré-limpeza, limpeza, secagem, expurgo ${ }^{6}$, armazenagem, segregação, blend e serviços aduaneiros.

Ao analisar a Tabela 2, percebe-se que, embora $100 \%$ dos terminais disponibilizem serviço de armazenagem aos clientes, menos de $40 \%$ deles dispõem de células específicas de segregação para grãos não modificados geneticamente. Sendo assim, pode-se afirmar que o armazenamento é uma função de apoio essencial à operação de transbordo. No entanto, muitas vezes não

6. Expurgo é a operação que visa eliminar insetos que se encontram nos produtos armazenados com a aplicação de defensivos agrícolas (GALLO et al., 2002). 
há interesse da empresa em fazer investimentos em armazéns, uma vez que o principal objetivo é aumentar a capacidade de transbordo.

Os serviços de pré-limpeza e limpeza são oferecidos por $46 \%$ e $53 \%$ dos terminais, respectivamente. Esses serviços são prestados quando os grãos são recebidos com muitas impurezas, principalmente folhagens que, ao passarem pelo processo de secagem, podem ser incendiados.

Já os serviços de secagem e expurgo são realizados por $46 \%$ e $38 \%$ dos terminais, respectivamente. Eles têm como objetivo diminuir a porcentagem de umidade dos grãos, até que alcance $13 \%$, padrão técnico mínimo necessário para que possam ser armazenados e comercializados. Ele é indicado para casos em que os grãos chegam infestados por insetos ou são armazenados por longos períodos.

Apenas 23\% dos terminais oferecem o serviço de blend que, segundo Carvalho (1998), é o procedimento de mistura de grãos de qualidades diferentes com o objetivo de manter o padrão mínimo necessário para comercializá-los, minimizando perdas qualitativas e quantitativas do produto.

De acordo com Sogabe (2010), as capacidades de recepção, expedição e armazenagem são os fatores que mais influenciam na operação de transbordo. No entanto, estas são compostas por equipamentos/processos de apoio, conforme apresentados na Tabela 3 .

Ao analisar a Tabela 3, percebe-se que o número de balanças de recepção é, normalmente, igual ou superior ao número de balanças de expedição. Essa característica se deve ao fato de a maioria dos terminais transbordarem grãos de um modal que apresente capacidade baixa para um modal que apresente capacidade elevada.

Já o número de tombadores é, obrigatoriamente, igual ou inferior ao número de moegas. Tombadores agilizam o processo de descarregamento dos grãos de carretas ou vagões, reduzindo o tempo da operação pela metade, comparada com aqueles terminais que não disponibilizam deste equipamento. Contata-se que o terminal que apresentou maior quantidade de tombadores também apresentou maior capacidade de recepção e movimentação anual.

As tulhas ou bicas de expedição são os equipamentos por onde os grãos são expedidos. Estes equipamentos limitam não somente a quantidade de expedição, como também podem comprometer a quantidade do produto, por meio de quebra de grãos. Os terminais que transbordam grãos para o modal hidroviário não necessitam de várias bicas ou carregadores de navios,

Tabela 3. Caracterização dos equipamentos de apoio ao transbordo dos terminais

\begin{tabular}{|c|c|c|c|c|c|}
\hline Terminal & $\begin{array}{c}\text { № de balanças de } \\
\text { recepção }\end{array}$ & № de moegas & № de tombadores & $\begin{array}{c}\text { № de tulhas ou bicas } \\
\text { de expedição }\end{array}$ & $\begin{array}{c}\text { № de balanças de } \\
\text { expedição }\end{array}$ \\
\hline $\mathrm{A}$ & 1 & 3 & 2 & 2 & 1 \\
\hline $\mathrm{B}$ & 1 & * & * & * & * \\
\hline $\mathrm{C}$ & 1 & 3 & * & 3 & 1 \\
\hline $\mathrm{D}$ & 1 & 3 & * & 1 & * \\
\hline E & 2 & 5 & 5 & 3 & * \\
\hline $\mathrm{F}$ & 2 & 1 & 1 & * & * \\
\hline G & 6 & 3 & * & 3 & 4 \\
\hline $\mathrm{H}$ & 11 & 3 & * & * & 6 \\
\hline $\mathrm{I}$ & 1 & 4 & 2 & 4 & 1 \\
\hline $\mathrm{J}$ & 3 & 2 & 2 & * & * \\
\hline K & 1 & 2 & 1 & 2 & 2 \\
\hline $\mathrm{L}$ & 2 & 12 & 12 & 5 & 1 \\
\hline $\mathrm{M}$ & 11 & 13 & 6 & 3 & 3 \\
\hline
\end{tabular}

* Não possui ou não foi informado.

Fonte: Dados da pesquisa. 
Quadro 2. Ilustração dos construtos utilizados na pesquisa de campo

Prazo

Fonte: Elaborada pelos autores.

uma vez que estes equipamentos têm capacidade nominal de expedição elevada. Este fato é corroborado pelos terminais E, G, H e J, que têm capacidade de expedição de $2.500 \mathrm{t} / \mathrm{h}, 3.000 \mathrm{t} / \mathrm{h}, 900 \mathrm{t} / \mathrm{h}$ e $3.750 \mathrm{t} / \mathrm{h}$, respectivamente.

\subsection{Análise das preferências declaradas pelos embarcadores}

A apresentação das alternativas aos entrevistados foi feito por meio de cartões que continham os construtos e respectivos níveis, em forma de figuras autoexplicativas, conforme apresentados de forma sintética no Quadro 2.

Na operacionalização do experimento, optou-se por não apresentar todas as combinações possíveis de níveis e construtos aos entrevistados, ou seja, utilizar o fatorial fracionário. Os resultados obtidos são resultantes do ordenamento pelos entrevistados de seis blocos com cinco cartões, de um total de oito, usando a técnica de blocos incompletos parcialmente balanceados sugerido por Souza (1999).

Frequentemente, uma só repetição de um experimento fatorial vai além dos recursos dos investigadores, ou dá mais precisão do que o necessário para a estimação dos efeitos principais (COCHRAN e COX, 1978 apud SOUZA, 1999).

O uso de experimentos em repetição fracionada foi proposto em 1945 por Finney ${ }^{7}$. Desde então, os projetos foram utilizados em muitas aplicações, particularmente em desenvolvimentos industriais. Sua principal atratividade é que permite incluir cinco ou mais fatores em um experimento de tamanho prático, de tal maneira que o investigador pode determinar rapidamente os efeitos dos fatores no resultado.

Os resultados do modelo estatístico são apresentados na Tabela 4 . O teste $t$ considera a significância dos parâmetros $\beta$, indicando que os resultados obtidos serão significativos se estiverem acima do valor determinado na Tabela $t$-student. O programa LMPC (SOUZA, 1999) utilizado considera o teste $\boldsymbol{t}$ com significância de $95 \%$ para estes parâmetros.

O construto Confiabilidade tem maior coeficiente de correlação, o que indica uma corre-

7. FINNEY, D. J. The fractional replication of factorial arrangements. Ann. Eugen., v. 12, p. 291-301, 1945. 
lação muito forte, significando que a população amostrada dá muita importância a esse atributo, e menor importância estatisticamente ao atributo flexibilidade, pois seu coeficiente de correlação é bem fraco. Segundo Shikimura (2006), uma associação muito forte esta entre 0,90 e 1,00, e uma correlação bem fraca, entre 0,00 e 0,19.

Em relação ao teste $t$ (teste de significância de um parâmetro), Marques (2003) enfatiza que valores acima de 2 são usualmente indicados como adequados para esse tipo de experimento. Observando os resultados, é possível verificar que o atributo Confiabilidade é estaticamente o mais significante para o entrevistado, 3,9806. Também se pode dizer que esse resultado mostra que existem diferenças significativas para o entrevistado escolher entre o nível 0 e 1 desse atributo. No caso do atributo Flexibilidade, tem o menor resultado no teste $t$, sendo o item com menor relevância para o entrevistado, o que também pode indicar que não existe diferença significativa que o faça escolher entre o nível 0 ou 1 do atributo. Isso é comprovado estatisticamente pelo baixo resultado, 0,0798 .

O próximo teste abordado foi o teste da Razão de Verossimilhança $L R=-2\left\{L(0)-L\left(\beta^{*}\right)\right\}$, que tem a finalidade de testar a hipótese de nulidade de todos os parâmetros simultaneamente. Segundo Ben-Akiva e Lerman (1985), se o valor LR for maior que o valor $\chi_{(\alpha, \mathrm{r})}^{2}$, então rejeita-se a hipótese de nulidade de todos os parâmetros simultaneamente. Nesse estudo, o resultado encontrado foi de 43,4515 para o teste LR; isso indica que a hipótese de nulidade deve ser rejeitada, portanto, que os parâmetros têm utilidade e são, consequentemente, relevantes.

$\mathrm{Na}$ sequência, é possível visualizar os resultados do teste da estatística $\rho^{2}$ (Pseudo Coeficiente de Determinação - Rho). Para Ortúzar e Willumsen (1990), a estatística $\rho^{2}$ tem seu valor teórico limitado de 0 a 1, mas seu valor entre 0,2 e 0,4 indica ajuste considerado excelente para o modelo logit multinomial. No caso do resultado encontrado nesse estudo, o Rho tem bom desempenho, a 0,1709.

Outro teste disponível no software LMPC de Souza (1999) é o de comparação das alternativas, com a finalidade de se conhecer qual combinação de atributos e cartões foi mais escolhida e testar a significância de cada alternativa (cartão apresentado) individualmente. Como resultado, obteve-se que todas as alternativas são significantes.

Também foi aplicado o teste do ponto crítico ou de sela. Obteve-se a resposta de que, estatisticamente, todos os níveis dos construtos são importantes para o entrevistado, pois ao combinar dois a dois os cinco construtos, todos atingiram o ponto de máximo local, e não de sela, podendo ser analisado na Tabela 4 .

Tabela 4. Resultados estatísticos relativos aos construtos

\begin{tabular}{lcccc}
\hline \multicolumn{1}{c}{ Construto } & Coeficiente & Erro & Teste $\mathbf{~}$ & IC $(\mathbf{t}=\mathbf{2 , 5 \% )}$ \\
\hline Prazo & 0,8614 & 0,2790 & 3,0880 & {$[0,304 ; 1,419]$} \\
Relações com cliente & 0,5384 & 0,2520 & 2,1366 & {$[0,034 ; 1,042]$} \\
Custo & 0,3299 & 0,2209 & 1,4939 & {$[-0,112 ; 0,772]$} \\
Confiabilidade & 0,9935 & 0,2496 & 3,9806 & {$[0,494 ; 1,493]$} \\
Flexibilidade de rotas & 0,0184 & 0,2304 & 0,0798 & {$[-0,442 ; 0,479]$} \\
\hline
\end{tabular}

Número de Entrevistas $=40 \quad$ Número de Casos $=120$

$\mathrm{F}($ Betas_0 $)=-127,1222 \quad \mathrm{~F}($ Betas_1 $)=-105,3964$

$\operatorname{LR}(-2[\mathrm{~F}(0)-\mathrm{F}(\mathrm{B})])=43,4515$

Rho $=0,1709 \quad$ Rho (Ajt) $=0,1316$

Fonte: Resultados da pesquisa. 


\begin{tabular}{|c|c|c|}
\hline Teste do Ponto Cn & : & Ponto de Máximo, Mínimo ou Sela \\
\hline $\operatorname{Beta}[1,2]=-34,524$ & $\Rightarrow$ & Ponto de Máximo Local ${ }^{* * *} \mathrm{CM}=0,1321$ \\
\hline $\operatorname{Beta}[1,3]=-39,344$ & $\Rightarrow$ & Ponto de Máximo Local *** CM $=0,1295$ \\
\hline $\operatorname{eta}[1,4]=-33,994$ & $\Rightarrow$ & Ponto de Máximo Local $* * * \mathrm{CM}=0,1748$ \\
\hline Beta $[1,5]=-3$ & $\Rightarrow$ & Ponto de Máximo Local $* * * C M=0,1232$ \\
\hline $\operatorname{Beta}[2,3]=-43,620$ & $\Rightarrow$ & Ponto de Máximo Local $* * * \mathrm{CM}=0,1163$ \\
\hline $\operatorname{Beta}[2,4]=-38,269$ & $\Rightarrow$ & Ponto de Máximo Local $* * * \mathrm{CM}=0,1563$ \\
\hline $\operatorname{Beta}[2,5]=-42,586$ & $\Rightarrow$ & Ponto de Máximo Local $* * * \mathrm{CM}=$ \\
\hline $\operatorname{Beta}[3,4]=-43,089$ & $\Rightarrow$ & Ponto de Máximo Local $* * * C M=0,1514$ \\
\hline $\operatorname{Beta}[3,5]=-47,406$ & $\Rightarrow$ & Ponto de Máximo Local ${ }^{* *} \mathrm{CM}=0,1102$ \\
\hline $\operatorname{Beta}[4,5]=-42,056$ & $\Rightarrow$ & Ponto de Máximo Local ${ }^{* *} \mathrm{CM}=0,1466$ \\
\hline
\end{tabular}

Finalizando a análise dos resultados obtidos com o software LMPC, conclui-se que os dados da Tabela 4 são significativos. Assim, a função utilidade é descrita da seguinte forma:

$$
\begin{aligned}
& \mathrm{FU}=\left(0,8614 \chi_{1}\right)+\left(0,5384 \chi_{2}\right)+ \\
& +\left(0,3299 \chi_{3}\right)+\left(0,9935 \chi_{4}\right)+\left(0,0184 \chi_{5}\right)
\end{aligned}
$$

Em que: FU= Função utilidade; $\chi_{1}=$ Prazo; $\chi_{2}=$ Relações com o cliente; $\chi_{3}=$ Custo; $\chi_{4}=$ Confiabilidade; $\chi_{5}=$ Flexibilidade.

$\mathrm{O}$ fato de os coeficientes serem todos positivos indica que, para os entrevistados, há um ganho ao se passar do construto de nível 0 para o construto de nível 1 dos respectivos construtos.

\subsection{Discussão das implicações dos resultados}

Segundo Meixel e Norbis (2008), os critérios mais seguidos na contratação de serviços de transporte, em escala mundial, são Confiança no serviço, Tempo em trânsito (Tempo) e Custos logísticos, em primeiro plano, seguidos de Índice de avarias, Disponibilidade de veículo/flexibilidade do serviço, Atendimento, Frete e Qualidade do serviço. Para os embarcadores industriais brasileiros, Martins et al. (2011) identificaram os construtos Segurança e a Confiabilidade como os de maior importância nos serviços prestados pelas transportadoras, seguidos por Prazo, Custo, Relação com o cliente e Atendimento a necessidades especiais dos clientes. Martins, Lobo e Pereira (2005) identificaram os construtos
Garantia, Consistência, Disponibilidade, Prazo e Confiabilidade. No caso do presente estudo, dentre os construtos apresentados, a prioridade manifestada foi declarada na seguinte ordem: Confiabilidade, Prazo, Relações com Cliente, Custo e Flexibilidade.

Os resultados refletem a preocupação dos embarcadores quanto às questões relativas às expectativas das operações próprias da logística, do cumprimento dos contratos e dos custos logísticos, bem como na qualidade e dotação dos sistemas de transporte. Inicialmente, entende-se que os embarcadores manifestam interesse de que as operações ocorram dentro de prazos esperados, com confiabilidade e custos competitivos. Além do mais, conforme indica Wanke (2012), a menor tolerância a baixos níveis de serviço menores e a aversão ao risco de roubo de cargas também refletem a tonelagem transportada anualmente.

Desta forma, os coeficientes na formatação dos serviços manifestados como desejados pelos embarcadores dão uma dimensão do nível de qualidade esperado da operação dos terminais intermodais. Esta alternativa pode até tornar-se mais cara, mas deve ser compensada pela maior confiabilidade, que permite redução de custos de armazenagem em áreas portuárias e perdas de embarque nos navios na exportação provocadas por atrasos nas operações e trânsito.

Por outro lado, esta racionalidade na tomada de decisão também pode ser discutida pelo ângulo da dotação dos sistemas de transporte. 
Desta maneira, os custos de transporte estão sendo considerados qualitativamente além dos fretes associados às modalidades, que são avaliados vis-a-vis aos custos referentes às características de qualidade dos serviços, que incluem velocidade e tempo total de entregas, confiabilidade e outros indicadores da logística.

No aspecto qualitativo, os sistemas de transporte devem disponibilizar serviços dentro das expectativas dos embarcadores. Além de ser um diferencial competitivo a favor do transportador atento a estas demandas, o aprimoramento da qualidade no transporte pode reverter-se em redução do custo do produto final, resultado da redução dos custos de transação e das perdas, por exemplo.

Scherer e Martins (2003) e Martins, Lobo e Pereira (2005) haviam identificado esta tendência de perda de importância relativa na preocupação dos embarcadores em relação ao custo ao pesquisarem os construtos desejados na contratação de operadores logísticos. Estes resultados indicam significativa transformação no mercado no que diz respeito aos atributos prioritários para a contratação de fretes. Historicamente, o mercado de fretes, no segmento de granéis agrícolas, priorizou o preço como o construto mais relevante, o que tornava o transporte uma commodity.

No entanto, valorizar as garantias que somente os grandes operadores podem dar implica priorizar contratos e relacionamentos de prazo mais longo. Isto sinaliza para o mercado que os grandes embarcadores estão negociando prioritariamente com empresas transportadoras com frotas próprias. Um reflexo imediato desta tendência poderá ser a redução da participação das agências de frete, negócios estabelecidos à base da desorganização e pulverização do segmento prestador de serviços, em que predomina o autônomo ("carreteiro") e, por consequência, destes transportadores que têm frota reduzida e muitas vezes restrita a um único veículo.

Por outro lado, este processo de qualificação dos serviços e profissionalização é necessário para o transporte rodoviário de cargas se manter competitivo frente à expansão recente, ainda que muitas vezes tímida e não tão disseminada, de outras modalidades. Neste novo cenário, parece patente que o autônomo tenha uma redução drástica de importância no mercado e fique cada vez mais dependente da subcontratação por empresas de transporte de cargas.

Há também o contexto das políticas públicas. O País muito discute a extrema concentração do transporte de cargas no transporte rodoviário, principalmente de produtos que teriam melhor alocação em outras modalidades, tais como a ferroviária e hidroviária. E isto pode não estar acontecendo, em grande parte, em razão do desempenho dos serviços prestados.

Neste aspecto, torna-se importante que as agências reguladoras dos serviços de transporte tenham ações mais compreensivas no sentido de aferir os serviços no composto completo que a logística deve oferecer, pois o que embarcadores sinalizaram neste estudo é que, mais do que simplesmente disponibilidade, eles precisam de serviços confiáveis, em termos de tempo em trânsito, mas também complementares, tais como os serviços de armazenagem e classificação. Neste sentido, pode ser cabível uma revisão dos papéis das agências reguladoras e de suas métricas de desempenho.

\section{Conclusão}

Este estudo procurou investigar quais são os construtos desejados pelos embarcadores nos serviços de terminais intermodais de granéis agrícolas. Esta resposta pode ajudar a compreender porque o País de dimensões continentais, que produz majoritariamente e movimenta produtos de baixo valor agregado a longas distâncias utiliza principalmente a modalidade rodoviária. Neste artigo, o transporte é analisado enquanto gestão de serviços, procurando entender como embarcadores formam expectativas quanto aos serviços.

Utilizando a técnica de Preferência Declarada, os embarcadores indicaram que, dentre os construtos apresentados, a prioridade foi manifes- 
tada na seguinte ordem: Confiabilidade, Prazo, Relações com Cliente, Custo e Flexibilidade.

Os resultados refletem preocupações dos embarcadores quanto ao cumprimento dos contratos e dos custos logísticos, bem como na qualidade e dotação dos sistemas de transporte. Inicialmente, entende-se que os embarcadores manifestam interesse que as operações ocorram dentro de prazos esperados, com confiabilidade no patamar de custos competitivo. Por um lado, os embarcadores têm pequena margem para erros, pois buscam minimizar custos com redução de armazenagem em áreas portuárias e perdas de embarque nos navios na exportação provocadas por atrasos nas operações e trânsito. Por outro lado, o uso do transporte unimodal, normalmente rodoviário, é mais seguro em termos dos prazos requeridos e do tempo total da operação.

Fundamentalmente, o estudo sinaliza, confirmando estudos anteriores, que, comparativamente, construtos associados à qualidade do serviço estão recebendo uma valoração superior ao custo (frete). Isto implica novas referências para o mercado de transporte, em que devem cada vez mais predominar aspectos da qualidade e desempenho do serviço, o que pode indicar aumento do uso de contratos e relacionamentos de longo-prazo. Como resultado das alterações no ambiente, pode-se antever maior participação de transportadoras, em substituição aos carreteiros, ou em sua subcontratação. Seria um passo importante para a profissionalização dos serviços de transporte e recuo no processo de commoditização do transporte.

\section{Referências bibliográficas}

ANTT. Agência Nacional de Transporte Terrestre. Pesquisa de avaliação da satisfação dos usuários dos serviços das empresas do transporte terrestre. Brasília, ANTT, 2005.

ALMEIDA, L. M. W. e GONÇALVES, M. B. A methodology to incorporate behavioral aspects in tripdistribution models with an application to estimate student flow. Environment and Planning A, v. 33, p. 11251138, 2001.
BEN-AKIVA, M. e LERMAN, S. R. Discrete Choice Analysis: theory and application to travel demand. New Jersey, Mit Press, 1985.

BALLOU, R. H. Gerenciamento da Cadeia de Suprimentos / Logística Empresarial. 5. ed. Porto Alegre: Bookman, 2006.

BIRD/ANTT. Banco Internacional de Reconstrução e Desenvolvimento/ Agência Nacional de Transporte Terrestre. Avaliação da demanda do transporte ferroviário de cargas no Brasil. Brasília, ANTT, 2006. (Estudo relativo ao Empréstimo № BR-4.188/BIRD)

BYRNS, R. T. Microeconomia. São Paulo: Makron Books, 1996.

CAIXETA-FILHO, J. V. A logística do escoamento da safra brasileira. CEPEA/USP, julho de 2006. Disponível em: $<$ www.cepea.esalq.usp.br/especialagro/EspecialAgro Cepea_7.doc>. Acesso em: 08 jul. 2011.

CAIXETA-FILHO, J. e GAMEIRO, A. H. (Orgs.). Transporte e Logística em Sistemas Agroindustriais. São Paulo: Atlas, 2001.

CALABREZI, S. R. da S. Mutimodalidade para o transporte de cargas: identificação de problemas em terminais visando à integração dos modais aéreo e rodoviário. Campinas: UEC, 2005.

CAMARGO, O. Identificação dos principais atributos considerados no transporte de cargas: estudo de caso no oeste paranaense. Tese de doutorado - Pós-graduação em Engenharia de Produção. Universidade Federal de Santa Catarina, Florianópolis, Brasil, 2000.

CARVALHO, V.D. Cafeicultura empresarial: produtividade e qualidade. Lavras: UFLA/FAEPE, 1998.

CERVO, A. L., BERVIAN, P. A. e DA SILVA, R. Metodologia científica. 6. ed. São Paulo: Pearson Prentice Hall, 2007.

COCHRAN, W. G. e COX, G. M. Diseños Experimentales. México: Trillas, 1978.

COLLIS, J. e HUSSEY, R. Business research: a practical guide for undergraduate and postgraduate students, 3. ed. Basingstoke: Palgrave Macmillan, 2009.

CRAIGHEAD, C. e MEREDITH J. Operations management research: evolution and alternative future paths. International Journal of Operations $\mathcal{E}$ Production Management, v. 28, n. 8, p. 710-726, 2008.

CSCMP - Council of Supply Chain Management Professionals. Glossary of Terms \& Definitions. Disponível em: <http://cscmp.org/digital/glossary/glossary.asp>. Acesso em: 5 mai. 2009. 
DALMAS, S. R. S. P., LOBO, D. S. e ROCHA JR, W. F. da. A Logística de Transporte Agróciola Multimodal da Região Oeste Paranaense. Informe Gepec (Impresso), v. 13, p. 154-169, 2009.

DEMARIA, M. O Operador de Transporte Multimodal como Fator de Otimização da Logística. Dissertação apresentada ao Programa de Pós-Graduação em Engenharia de Produção da Universidade Federal de Santa Catarina. Florianópolis, 2004.

DORNIER, P. P., ERNST, R. e FENDER, M. P. K. Logística e operações globais: texto e casos. São Paulo: Atlas, 2000.

GALLO, D. et al. Entomologia agrícola. Piracicaba, FEALQ, 2002.

HAIR, J. F. et al. Multivariate Data Analysis, Upper Saddle River, NJ: Prentice Hall, 2005.

LOBO, D. da S. e CONTE, H.. Comparison of logistics strategies of two cooperatives in the poultry sector using Stated Preference Technique. In: 23rd Annual Production and Operations Management Conference, 2012, Chicago - EUA. Proceedings of..., 2012.

LOBO, D. S. Dimensionamento e otimização locacional de unidades de educação infantil. Tese de doutorado. UFSC. 2003.

LOUVIERE, J. J., HENSHER, D.A. e SWAIT, J. D. Stated Choice Methods: analysis and application. Cambridge: Cambridge University Press, 2000.

MALHOTRA, N. K. Marketing Research: An Applied Orientation, Upper Saddlle River, NJ: Prentice Hall, 2001.

MAPA. Ministério da Agricultura, pecuária e Abastecimento. 2011. Disponível em: <http://www. agricultura.gov.br> Acesso em: 01 mai. 2011.

MARCONI, M. A. e LAKATOS, E. M. Técnicas de Pesquisa. 7. ed. São Paulo: Atlas, 2008.

MARQUES, K. W. B. Preferência declarada aplicada à alocação ótima de alunos às escolas: um estudo de caso. Tese de doutorado. UFPR, Curitiba.(2003).

MARTINS, R. S. e CYPRIANO, L. A. Logística Pública: Discussão e Evidências dos Impactos dos Sistemas de Transportes para os Agronegócios Brasileiros e para o Desenvolvimento Regional. In: MOURA, A. D. e SILVA JÚNIOR, A. G. (Ed.). Competitividade do Agronegócio Brasileiro em Mercados Globalizados. Viçosa, UFV, 2004. 262p.

MARTINS, R. S. et al. Investment Shortages in the Brazilian Transportation System: Evidence from the Agribusiness Case. In: 52nd Annual North American
Meetings of the Regional Science Association International, 2005, Las Vegas - EUA. Proceedings of..., 2005.

MARTINS, R. S., LOBO, D. S. e PEREIRA, S. M. Atributos relevantes no transporte de granéis agrícolas: Preferência declarada pelos embarcadores. Revista de Economia e Agronegócio, Viçosa - UFV, v. 32, n. 2, p. 173-192, 2005.

MARTINS, R. S. e LEMOS, M. B. Corredor Centro-Leste: sistemas de transporte de Minas Gerais na perspectivas dos eixos de desenvolvimento e integração. Belo Horizonte: UFMG/Cedeplar, 2006.

MARTINS, R. S. et al. Logistics Managers Stated Preferences for Supply Management Attributes for the Case of Inns in Brazil, International Journal of Tourism and Hospitality Research, v. 19, n. 2, p. 323-339, 2008.

MARTINS, R. S. et al. Gestão do Transporte Orientada para os Clientes: Nível de Serviço Desejado e Percebido. RAC. Revista de Administração Contemporânea, v. 15, p. 1100-1119, 2011.

MARTINS, R. S. e LOBO, D. S. Desired and Perceived Levels of Service in Transport Contracts. In: Production and Operation Management Society (POMS) Annual Conference, 2011, Reno, EUA. Proceedings of..., 2011.

MASON, S. J. et al. Integrating the warehousing and transportation functions of the supply chain. Transportation Research - Part E, p. 141-159, 2003.

McCANN, P. A proof of the relationship between optimal vehicle size, haulage length and the structure of distance-transport costs. Transportation Research Part A, v. 35, p. 671-693, 2001.

MEIXELL, M. e NORBIS, M. A review of the transportation mode choice and carrier selection literature. The International Journal of Logistics Management, v. 19, n. 2, p. 183-211, 2008.

NEUSCHEL, R. P. e RUSSELL, D. M. Customer driven marketing in the transportation/logistics industry. The International Journal of Logistics Management, v. 9, n. 2, p. 99-106, 1998.

NG, B., FERRIN, B. G. e PEARSON, J. N. The role of purchasing/transportation in cycle time reduction. International Journal of Operation and Production Management, v. 17, n. 62, p. 574-591, 1997.

NOVAES, A. G. Logística e gerenciamento da cadeia de distribuição. Rio de Janeiro: Elsevier, 2007.

OJIMA, A. L. R. O. Análise da movimentação logística e competitividade da soja brasileira: uma aplicação de um modelo de equilíbrio espacial de programação quadrática. Dissertação (mestrado) - Universidade 
Estadual de Campinas, Faculdade de Engenharia Elétrica e de Computação, 2004.

ORTÚZAR, J. D. e WILLUMSEN, L. G. Modeling transport. John Wiley \& Sons. England, 1990.

ORTÚZAR, J. D. Modelos de demanda de transporte. 2. ed. Santiago: Ediciones Universidad Católica de Chile, 1998.

SANTOS, A. B. Avaliação da eficiência operacional dos Terminais Intermodais da cadeia logística de grãos brasileira. 2012. 125 f. Dissertação (Mestrado em Administração) - Departamento de Economia e Administração, Universidade Federal de Mato Grosso do Sul, Campo Grande, 2012.

SCHERER, A. e MARTINS, R. S. Atributos da prestação de serviços para operações logísticas de commodities agrícolas na visão dos embarcadores. Economia $e$ Agronegócios. Viçosa, UFV, v. 1, n. 4, p. 461-488, 2003.

SCHLUTER, M. e SENA, L. A. S. As decisões de aquisição de serviços de transportes do pequeno varejista. In: ANPET/CNT. Transporte em ação IV, São Paulo, ANPET/CNT, 1999.

SCHMIDT, F. e LOBO, D. S. A aviação agrícola no Brasil: Um modelo para seleção de aviões com o uso de programação linear. In: Rinaldi, R. N. (Org.). Perspectivas do Desenvolvimento Regional \& Agronegócio. Cascavel: EDUNIOESTE, 2009, p. 273-292.

SOGABE, V. P. Caracterização do desempenho operacional em terminais intermodais de escoamento de grãos: um estudo multicaso no corredor centro-oeste. 2010. 122 f. Dissertação (Mestrado em Administração) - Departamento de Economia e Administração, Universidade Federal de Mato Grosso do Sul, Campo Grande, 2010.

SOUZA, O. A. de. Delineamento experimental em ensaios fatoriais utilizados em preferência declarada. Tese (Doutorado) - Engenharia de Produção/Universidade Federal de Santa Catarina. Florianópolis. 1999.

VALENTE, A. M., PASSAGLIA, E. e NOVAES, A. G. Gerenciamento de transporte e frotas. Ed. Pioneira, 2008.

WANKE, P. F. Fatores de satisfação com o uso de autônomos no transporte rodoviário de cargas. Produção, v. 22, n. 3, p. 584-595, maio/ago. 2012.

WANKE, P. F. e ZINN, W. Strategic logistics decision making, International Journal of Physical Distribution $\mathcal{E}$ Logistics Management, v. 34, Iss: 6, p. 466-478, 2004. 